\title{
DIRECTIVOS DOCENTES RESILIENTES
}

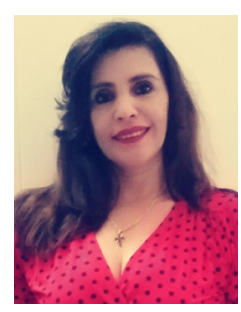

Luz Dary Franco Amado*

Universidad Metropolitana de Educación, Ciencia y Tecnología, Panamá

luzdfa17@hotmail.com

\section{RESUMEN}

En toda Institución Educativa la gestión directiva, académica, administrativa y comunitaria recae directamente en el equipo de Directivos Docentes, en calidad de rectores o coordinadores. Ante esta gran responsabilidad se hace necesario diseñar una Propuesta de Gestión Directiva Resiliente que facilite la eficacia y la eficiencia en su desempeño laboral. El presente artículo informa sobre los avances obtenidos en la investigación, originada dentro del marco del Programa de Doctorado en la Universidad Metropolitana de Ciencia y Tecnología, UMECIT, titulada "Directivos docentes resilientes, una propuesta para enfrentar la realidad educativa al interior de las instituciones educativas oficiales del municipio de Bucaramanga, Colombia”. Para dar cuenta de la investigación en curso se aborda en primera instancia los objetivos rectores de la investigación. Se presenta de manera sucinta la fundamentación teórica sobre los modelos de gestión directiva a nivel internacional, regional y local y la resiliencia como eje articulador de las competencias funcionales y comportamentales. Seguidamente se expone la metodología seleccionada para direccionar el proceso investigativo. Luego se muestran los principales resultados obtenidos con su correspondiente discusión e interpretación en función de los objetivos específicos. Por último las consideraciones finales a tener en cuenta en la estructuración del producto final de la investigación.

Palabras clave: gestión directiva, resiliencia, directivo docente.

\section{RESILIENT TEACHING DIRECTIVES ABSTRACT}

In all Educational Institutions, the directive, academic, administrative and community management falls directly on the team of Teaching Directors, as rectors or coordinators. Given this great responsibility, it is necessary to design a Resilient Management Proposal that facilitates

\footnotetext{
*Licenciada en Ciencias de la Educación con Especialidad en Administración Educativa de la Universidad Cooperativa de Colombia, sede Bucaramanga. Especialista en Gerencia de Instituciones Educativas de la Universidad del Tolima. Magíster en Educación de la Universidad del Tolima. Doctora en Ciencias de la Educación, con la Universidad Metropolitana de Ciencia y Tecnología (UMECIT), Panamá.
} 
effectiveness and efficiency in their work performance. This article reports on the progress made in the research, originated within the framework of the Doctoral Program at the Metropolitan University of Science and Technology, UMECIT, entitled "Resilient teaching managers, a proposal to face the educational reality within educational institutions officials from the municipality of Bucaramanga, Colombia". In order to account for the ongoing research, the guiding objectives of the research are first addressed. The theoretical foundation on managerial management models at the international, regional and local levels is briefly presented and resilience as the articulating axis of functional and behavioral competences. Next, the selected methodology to direct the research process is exposed. Then the main results obtained will be considered with their corresponding discussion and interpretation based on the specific objectives. Finally the final conclusions to take into account in structuring the final product of the investigation.

Key words: managerial management, resilience, teaching manager.

\section{INTRODUCCIÓN}

La resiliencia debería entonces inspirarnos mucha humildad, apertura de espíritu y discernimiento. (Vanistendael)

En Colombia, los directivos docentes de las Instituciones Educativas son, según lo contempla la Ley general de Educación, que rige actualmente, "los educadores que ejerzan funciones de dirección, de coordinación, de supervisión e inspección, de programación y de asesoría,..”. (Ley 115, capitulo 5, art.126). Como se aprecia son las personas encargadas de direccionar los procesos de gestión directiva, académica, administrativa y comunitaria, tarea fundamental en el ejercicio de la búsqueda del mejoramiento y calidad educativa.

De igual forma, el directivo docente (DD) tiene bajo su responsabilidad el cumplimiento de una serie de funciones que van más allá del saber o dominio del conocimiento porque incluye sus actitudes y comportamientos que fortalecen la funcionalidad del centro educativo que precede, como lo precisa El Ministerio de Educación Nacional (MEN):

Los directivos docentes tienen la responsabilidad del funcionamiento de la organización escolar. Para ello, realizan actividades de dirección, planeación, coordinación, administración, orientación y programación en las instituciones educativas. Corresponde además a los directivos docentes la función de orientar a la comunidad educativa (docentes, estudiantes, padres de familia y personal administrativo) hacia el logro de las metas colectivas, lo que incluye, entre otras cosas, que el directivo docente conozca y oriente el enfoque pedagógico de la institución. (MEN, 2008, 
p. 14).

Por lo tanto en la cotidianidad, los DD se ven enfrentados a ejercer un liderazgo en todo tipo de situaciones de orden académico, disciplinar, ambiente o clima organizacional, en fin, sortear todos los eventos que se presentan, lo cual les puede llegar a generar relaciones estresantes y tensas porque las decisiones que toman no a toda la comunidad educativa les agradan, entonces es bien difícil el direccionar o coordinar en el contexto educativo. Se observa que el espectro de gestión se ha ampliado, va más allá de la planeación, ejecución y evaluación del Proyecto Pedagógico Institucional (PEI), implica además, atender varias aristas que tienen que ver con el capital humano que tienen a su cargo.

En atención a esto, se requiere contar con una gestión que favorezca su desempeño personal, profesional, laboral y social, razón de ser del Proyecto de investigación. Esta propuesta requiere tener como elemento transversal la Resiliencia, entendida como: "la capacidad de recuperarse, sobreponerse y adaptarse con éxito frente a las adversidades y de desarrollar competencia social, académica y vocacional pese a estar expuesto a un estrés grave o simplemente a las tensiones inherentes al mundo de hoy" (Henderson y Milstein, 2003, p.26). Porque El DD en su praxis se relaciona con profesores, estudiantes, padres de familia, pares, jefes inmediatos y comunidad en general y enfrenta situaciones adversas, conflictos y dificultades que sólo una persona resiliente, capaz de sortearlas de una manera asertiva y proactiva podrá salir adelante, liderar procesos académicos, comunitarios, financieros, y administrativos, como la ley, el Estado y la comunidad educativa le exige. (Figura 1).

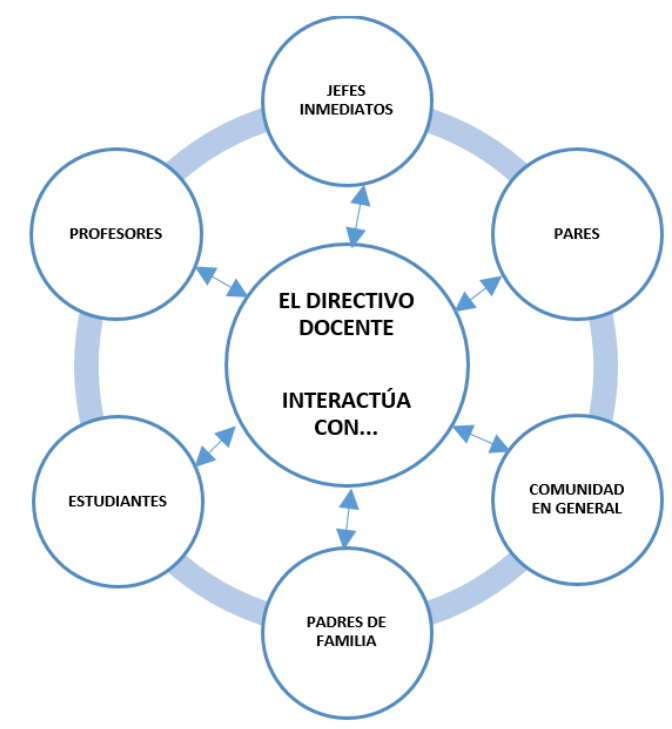

Figura 1. El Directivo Docente interactúa en la cotidianidad con diferentes personas del entorno escolar. Fuente: elaboración propia 
El objetivo general que orienta el proceso investigativo es: analizar la gestión del directivo docente en las Instituciones Educativas de la ciudad de Bucaramanga como fundamento de la propuesta "directivos docentes resilientes". Los objetivos específicos que apoyan su desarrollo son: establecer los elementos que constituyen la propuesta de gestión directiva resiliente para los directivos docentes de las instituciones educativas oficiales de la ciudad de Bucaramanga acordes con la normatividad colombiana, la teoría y las necesidades de la comunidad educativa; examinar las competencias existentes en las áreas de gestión de directivos docentes de las instituciones educativas oficiales de la ciudad de Bucaramanga acordes con la norma vigente establecida por el MEN y su evidencia en la praxis institucional ; construir la propuesta del perfil Resiliente de los directivos docentes de instituciones educativas oficiales del municipio de Bucaramanga que asegure una gestión de calidad y por último, diseñar una propuesta de gestión resiliente para los directivos docentes que fortalezca su desempeño al interior de las instituciones educativas del sector oficial de Bucaramanga acorde con la normatividad y las exigencias de calidad educativa en Colombia.

\section{FUNDAMENTACIÓN TEÓRICA}

"Nuestra escuela debería ser una escuela resiliente donde proliferaran múltiples hilos que enhebraran vocabularios de esperanza"

$$
\text { (Forés, A., y Grané). }
$$

Cómo fundamentos teóricos se considera importante tener en cuenta los modelos de gestión directiva a nivel internacional (Europa), a nivel regional (Latinoamérica) y a nivel nacional (Colombia), que a lo largo de la historia de la educación han surgido y tienen gran influencia en la concepción administrativa de las Instituciones Educativas. De igual forma se retoma el constructo Resiliencia, su trayectoria conceptual a raíz de los principales autores que se han dedicado a su génesis y su vínculo directo con los entornos educativos.

En cuanto a sistemas de gestión en Europa, al realizar el rastreo bibliográfico se considera importante tener en cuenta los siguientes referentes que ilustran la investigación.

\section{Modelos teóricos y modelos políticos.}

De una manera práctica, analítica y contextualizada Egido G. (2006), expone tres teorías sobre el director escolar: La científico- técnica, la interpretativa y la crítica; de igual forma presenta los 
modelos políticos en cuanto a directivos escolares en tres países: Francia, Reino unido y España que orientan la reflexión sobre el papel protagónico de los directivos docentes a nivel internacional. El rol del directivo docente en el modelo Perspectivo científico técnica es más gerente que educador; dentro de la Perspectiva interpretativa hace las veces de líder que orienta, gestiona y estimula el actuar de toda la comunidad y en la Perspectiva crítica permite el actuar, la participación y la criticidad. A su vez, dentro de los modelos políticos se encuentra que en Francia el DD ingresa a ejercer su labor por concurso, tiene autoridad y poder, recibe capacitación. En el Reino Unido, supera pruebas, lidera aspectos curriculares y pedagógicos y maneja presupuesto. En España: Sus funciones son restringidas y supervisadas por la Administración Educativa y el Consejo escolar, elige los integrantes de su equipo directivo

\section{Modelos de gestión directiva por competencias.}

Dentro de la investigación realizada por Javier M. Valle J y Cynthia A. Martínez (2010) en la Universidad Autónoma de Madrid titulada: La dirección de centros escolares en Europa en perspectiva comparada ¿De los modelos tradicionales a un "meta-modelo" supranacional? , se encuentra un comparativo de cuatro modelos de dirección: mediterráneo, nórdico, continental y anglosajón. En cada uno de ellos se identifican las competencias que debe desarrollar y evidenciar en su labor el director de los centros educativos. Se resaltan las siguientes apreciaciones.

$\checkmark$ El director de los centros escolares tiene un papel protagónico en el ámbito administrativo y pedagógico, toda vez que debe atender múltiples tareas que implican su dedicación y responsabilidad constante, independientemente del modelo de dirección que se desarrolle en el contexto geográfico y social.

$\checkmark$ Los cuatro modelos expuestos: mediterráneo, continental, anglosajón y nórdico, tienen diferencias entre sí pero a su vez mantienen un hilo conductor relacionado con la administración, control y evaluación de recursos siempre tendientes a cumplir con unos objetivos previamente establecidos.

$\checkmark$ Se resalta la importancia otorgada al director como el gestor de un ambiente o clima laboral adecuado, un manejo asertivo de las comunicaciones y el líder del equipo de trabajo. 


\section{Historicidad de los sistemas de gestión educativa en Latinoamérica.}

Es importante partir de un referente histórico de los diversos sistemas de gestión al interior de las instituciones educativas en Latinoamérica y para ello se retoma el informe presentado por Cassasus a la UNESCO en el año 1999 que figura en la tabla 1.

Tabla 1. Retrospectiva Sistemas de Gestión en Latinoamérica

\begin{tabular}{|c|c|c|}
\hline $\begin{array}{l}\text { SISTEMA DE } \\
\text { GESTIÓN }\end{array}$ & $\begin{array}{l}\text { PENSADORES MÁS } \\
\text { REPRESENTATIVOS }\end{array}$ & CARACTERÍSTICAS GENERALES \\
\hline $\begin{array}{l}\text { NORMATIVO } \\
\text { (Años } 50 \text { hasta inicio de } \\
\text { los 70) }\end{array}$ & JORGE AHUMADA & $\begin{array}{l}\text { Vertical, planificado, sujeta a planes nacionales } \\
\text { de desarrollo, abstracto. Aplicación de técnicas de } \\
\text { proyección hacía un futuro único y cierto, de una línea } \\
\text { tradicional. }\end{array}$ \\
\hline $\begin{array}{l}\text { PROSPECTIVO } \\
\text { (Mediados años 70) }\end{array}$ & MICHEL GODET & $\begin{array}{l}\text { Basado en un futuro múltiple e incierto. Inicio de } \\
\text { estudios comparativos y de programas regionales, } \\
\text { como por ejemplo el Programa Regional de Desarrollo } \\
\text { Educativo (Prede) asociados a la Organización de los } \\
\text { Estados Americanos (OEA) o el Proyecto Principal } \\
\text { de Educación asociados con la Organización de las } \\
\text { Naciones Unidas para la Educación, la Ciencia y la } \\
\text { Cultura (Unesco). }\end{array}$ \\
\hline $\begin{array}{l}\text { ESTRATÉGICO } \\
\text { (Principios de los 80) }\end{array}$ & CARLOS MATUS & $\begin{array}{l}\text { Tomar la organización a través de una identidad } \\
\text { institucional que pone en relieve la misión, visión, } \\
\text { las fortalezas, debilidades, oportunidades y amenazas. } \\
\text { Considera el contexto como elemento fundamental que } \\
\text { es dinámico y cambiante. }\end{array}$ \\
\hline $\begin{array}{l}\text { CALIDAD TOTAL } \\
\text { (Años 90) }\end{array}$ & $\begin{array}{l}\text { JOSEPH JURAN, EDWARD } \\
\text { DEMING, PHILLIPS CROSBY } \\
\text { Y PETER SENGE }\end{array}$ & $\begin{array}{l}\text { Sus componentes centrales son, por una parte, la } \\
\text { identificación de los usuarios y de sus necesidades, } \\
\text { el diseño de normas y estándares de calidad, el } \\
\text { diseño de procesos que conduzcan hacia la calidad, la } \\
\text { mejora continua de las distintas partes del proceso y } \\
\text { la reducción de los márgenes de error que hacen más } \\
\text { caros los procesos. } \\
\text { Por ello, se generaliza el desarrollo de sistemas de } \\
\text { medición y evaluación de la calidad de la educación. } \\
\text { La visión de la calidad total es a la vez una preocupación } \\
\text { por el resultado y por los procesos. } \\
\text { En la práctica, la perspectiva de gestión de Calidad } \\
\text { Total en los sistemas educativos se orienta a mejorar } \\
\text { los procesos mediante acciones tendientes, entre otras, } \\
\text { a disminuir la burocracia, disminuir costos, mayor } \\
\text { flexibilidad administrativa y operacional, aprendizaje } \\
\text { continuo, aumento de productividad, creatividad en los } \\
\text { procesos. } \\
\text { Entre las prácticas de la gestión de los sistemas } \\
\text { educativos en la segunda mitad de los años } 90 \text { prevalece } \\
\text { principalmente la perspectiva estratégica clásica } \\
\text { combinada con la perspectiva de Calidad Total. }\end{array}$ \\
\hline
\end{tabular}




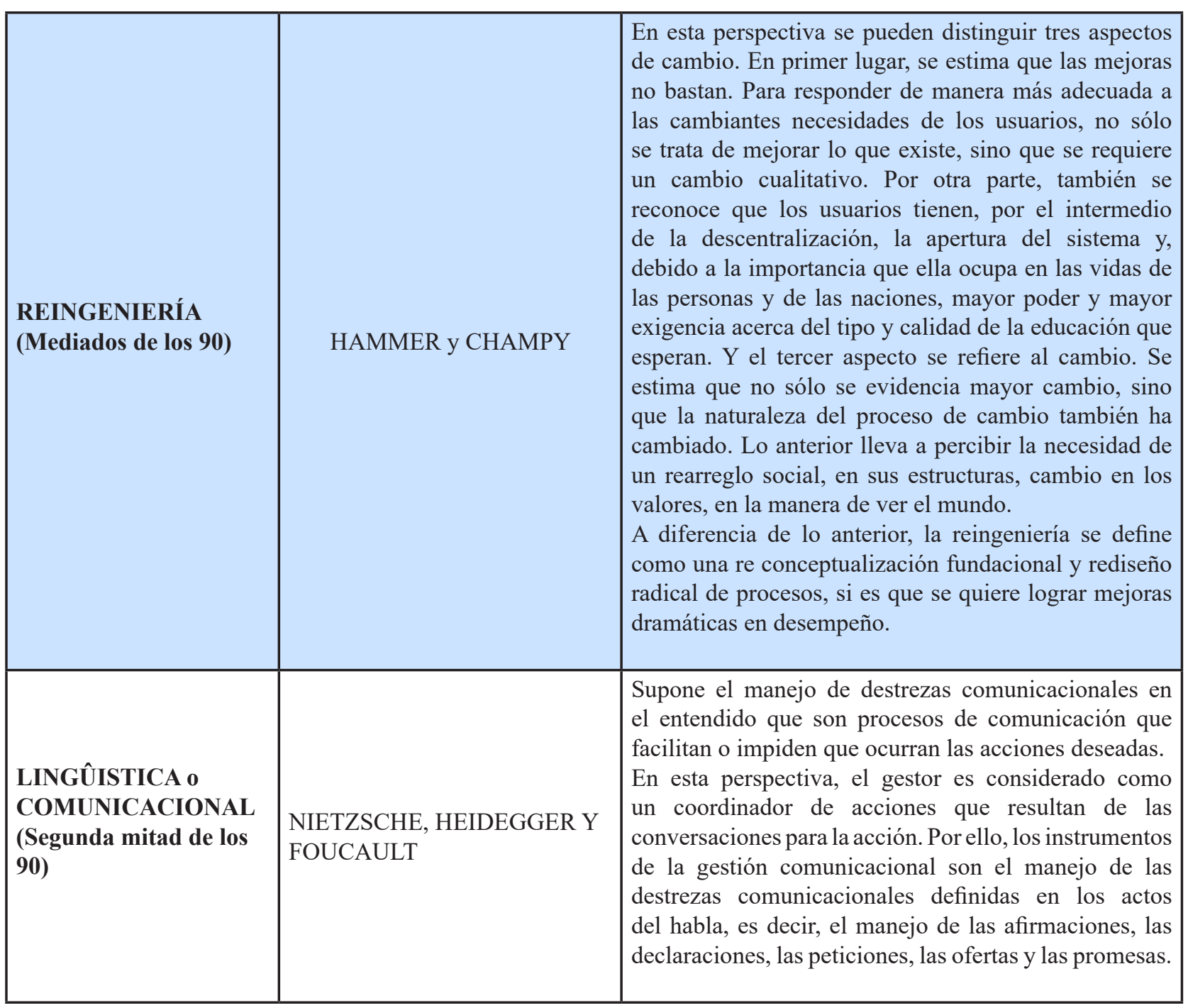

Fuente: elaboración propia a partir de Cassasus (1999).

Se observa que la cultura institucional ha sido cambiante y por ende se deduce que el papel del DD ha sido permeado por cada uno de los tipos de gestión que ha enfrentado. De un modelo de gestión vertical, autoritario, con organigramas institucionales rígidos se ha llegado al manejo organizacional dinámico, que admite organigramas tipo horizontal y circular, donde la autoridad no la ejerce el cargo sino la persona que lidera y acompaña en los diferentes procesos a la comunidad institucional.

\section{Función del directivo docente}

En una institución Educativa sus mayores representantes y quienes deben afrontar la corresponsabilidad del proceso formativo son los directivos docentes para quienes de manera muy explícita Borden (2009) en el documento titulado "El liderazgo del director escolar para el 
mejoramiento de la calidad educativa" que sirvió de base para una reunión de Empresarios por la Educación, presenta los grandes retos que deben asumir. (Figura 2)

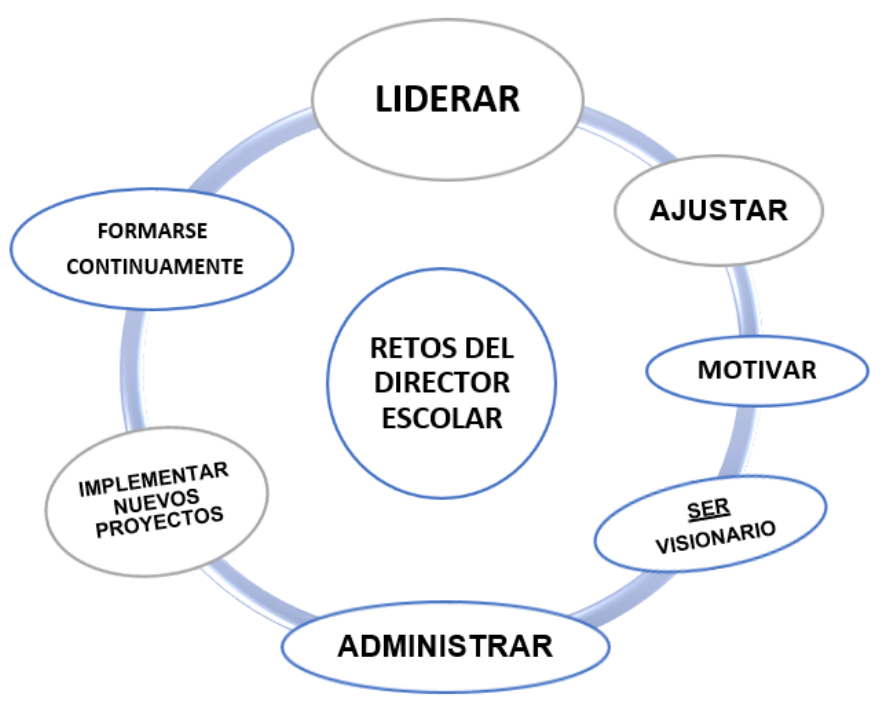

Figura 2. Retos del Directivo Docente.

Fuente: elaboración propia a partir de Borden M. (2009)

Se resaltan como fundamentales el liderar y administrar, funciones que se pueden y deben asumir simultáneamente, puesto que el liderazgo permite generar nuevas ideas, nuevos caminos, nuevas estrategias que para su implementación requieren de elementos, recursos y logística particular y en su consecución, manejo y control interviene la fase de administrador del DD.

De igual forma, Borden (2006) plantea en su trabajo titulado: Directores de Escuela en América Latina y el Caribe: ¿Líderes del Cambio o Sujetos a Cambio?, consideraciones relevantes para la investigación.

$\checkmark$ En América Latina y el Caribe la visión de las escuelas debe cambiar, deben pasar de una dependencia total, limitadas simplemente a reproducir y cumplir los mandatos, a ser centros donde se generen ideas, cambios y mejoras en la forma de educar.

$\checkmark$ Son los directores escolares quienes deben asumir y liderar los procesos pedagógicos al interior de sus centros para lograr avances significativos.

$\checkmark$ Es imprescindible que se cumpla lo expuesto en las directrices de proyectos educativos de algunos países como Colombia, México, Nicaragua y otros, donde se promulga mayor protagonismo a la comunidad educativa: profesores, padres de familia y estudiantes.

$\checkmark$ Las propuestas y programas requieren tener continuidad por lo tanto no es conveniente que estén sujetas a las políticas del gobierno en turno, puesto que esto interfiere en su pleno desarrollo, eficacia y efectividad. 


\section{La Gestión Directiva en la escuela}

Los procesos directivos se centran en orientar y organizar la vida escolar, a lo largo de los años se han perfilado dos estilos bien marcados: la administración escolar y la gestión educativa estratégica, que de manera puntual se presentan en la tabla 2.

Tabla 2. Rasgos de la Administración Escolar y la Gestión Educativa Estratégica.

\begin{tabular}{|c|c|}
\hline ADMINISTRACIÓN ESCOLAR & GESTIÓN EDUCATIVA ESTRATÉGICA \\
\hline 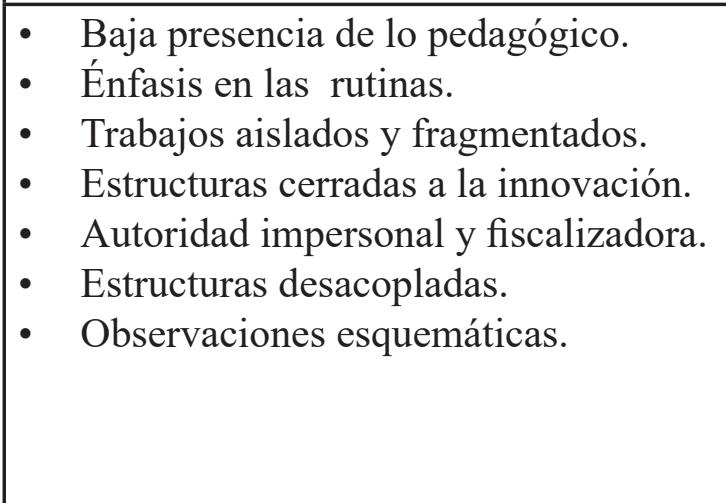 & $\begin{array}{l}\text { - Centralidad de lo pedagógico. } \\
\text { - } \text { Habilidades para trabajar con la compleji- } \\
\text { dad. } \\
\text { - } \text { Trabajo en equipo. } \\
\text { - } \text { Asertura al aprendizaje y la innovación. } \\
\text { zados. } \\
\text { - } \text { Culturas organizacionales cohesionadas } \\
\text { por una visión de futuro. } \\
\text { Intervenciones sistémicas y estratégicas. }\end{array}$ \\
\hline
\end{tabular}

Fuente: Gestión educativa estratégica módulo 2. IIPE UNESCO, (2000, p.15).

$\mathrm{Al}$ observar las dos posiciones que puede tomar un director escolar se encuentran diferencias bastante marcadas, toda vez que la misión de dirigir centrado en lo administrativo denota una función controladora, donde se realizan las mismas actividades, con los mismos protagonistas y podría pensarse que en los mismos momentos, de una forma repetitiva, rutinaria y poco innovadora, espacios disciplinariamente controlados sin oportunidad del enriquecimiento pedagógico. Todo lo contrario genera el asumir una misión de gestión educativa, puesto que se presume un rol del director más comprometido, más cercano y participativo de los procesos que se generan al interior de la escuela, como agente de cambio, de creación y mejoramiento.

De manera puntual Taylor en Gvirtz, S. y Podestá (2010) presenta las diferentes facetas que ejerce un director de escuela en su cotidianidad, las cuales titula "las metáforas" que a continuación se enuncian.

$\checkmark$ Malabarista, debe mantener todo en perfecto equilibrio.

$\checkmark$ Jardinero, dedicado al cuidado constante de sus alumnos y docentes, como un jardinero a sus plantas.

$\checkmark$ Director de orquesta, en quien todos fijan su mirada para que dirija sus pasos.

$\checkmark$ Un ancla, para sujetar y dar sostén.

$\checkmark$ Un doctor, que atiende en el día a día las diferentes dolencias de los integrantes de la comunidad (familiar, social, de salud, económica, entre otras). 
$\checkmark$ El detective, que investiga, sigue rastros, recoge información.

$\checkmark$ El paciente, que en silencio también sobrelleva dificultades (familiares, sociales, de salud, económicas).

Se reafirma una vez más que la labor de un directivo docente es bastante ardua y requiere tener un perfil multifacético que le permita cumplir de manera eficaz y efectiva con su trabajo.

\section{Características del rector o director de un establecimiento educativo en proceso de} mejoramiento continuo en Colombia

En el contexto nacional se establecen una serie de características que debe tener y evidenciar en su labor cotidiana el director de una Institución Educativa, las cuales se retoman de la Guía 34 del Ministerio de Educación Nacional (2008). Ver tabla 3.

Tabla 3. Características del Directivo Docente en Colombia.

\begin{tabular}{|c|c|}
\hline $\begin{array}{l}\text { Cree en la educación inclusiva como estrategia } \\
\text { fundamental para acceder al conocimiento y el } \\
\text { desarrollo. }\end{array}$ & $\begin{array}{l}\text { Lidera sus equipos: directivo, docente y } \\
\text { administrativo para que se involucren en la } \\
\text { construcción y desarrollo de la identidad } \\
\text { institucional, el PEI, los planes de estudio y } \\
\text { mejoramiento. }\end{array}$ \\
\hline $\begin{array}{l}\text { Confía en la capacidad de todos los estudiantes } \\
\text { para aprender y liderar la búsqueda y puesta en } \\
\text { marcha de estrategias pedagógica innovadoras } \\
\text { y pertinentes. }\end{array}$ & $\begin{array}{l}\text { Logra que cada persona que trabaja en el } \\
\text { establecimiento o centro educativo se sienta } \\
\text { parte del equipo y comparta sus principios y } \\
\text { formas de actuar. }\end{array}$ \\
\hline $\begin{array}{l}\text { Es proactivo y flexible (se permite cambiar, } \\
\text { innovar y afrontar la complejidad). }\end{array}$ & $\begin{array}{l}\text { Verifica el cumplimiento de las funciones y } \\
\text { tareas de cada una de las personas a su cargo. }\end{array}$ \\
\hline $\begin{array}{l}\text { Tiene un elevado grado de compromiso y } \\
\text { motivación. }\end{array}$ & $\begin{array}{l}\text { Evalúa periódicamente el desempeño de } \\
\text { docentes, directivos y personal administrativo y } \\
\text { les da retroalimentación pertinente y oportuna } \\
\text { para que puedan superar sus dificultades. }\end{array}$ \\
\hline $\begin{array}{l}\text { Estimula y reconoce el buen desempeño de } \\
\text { estudiantes y docentes. }\end{array}$ & $\begin{array}{l}\text { Conoce las características de los estudiantes, sus } \\
\text { familias y el entorno de la institución educativa, } \\
\text { así como su evolución en el tiempo. }\end{array}$ \\
\hline $\begin{array}{l}\text { Dirige sus esfuerzos a los aspectos en los que } \\
\text { puede incidir. No se siente impotente ante los } \\
\text { problemas que no puede solucionar. }\end{array}$ & $\begin{array}{l}\text { Sabe cuáles son los aprendizajes y competencias } \\
\text { básicas que todos los estudiantes deben } \\
\text { desarrollar en cada momento de su proceso } \\
\text { educativo. }\end{array}$ \\
\hline $\begin{array}{l}\text { Usa datos e información para tomar decisiones } \\
\text { de manera responsable. }\end{array}$ & $\begin{array}{l}\text { Facilita la apertura y permanencia de espacios } \\
\text { de participación y concertación de la comunidad } \\
\text { educativa. }\end{array}$ \\
\hline
\end{tabular}


Planea su trabajo y lidera la formulación, ejecución y seguimiento de planes y proyectos.

Sabe que debe aprender continuamente para tener más y mejores herramientas teóricas y metodológicas para ejercer su labor.

Promueve el sentido de pertenencia al establecimiento educativo.

Moviliza conocimientos y esquemas de acción para solucionar los problemas.

Fomenta el trabajo en equipo.
Establece canales de comunicación apropiados que permiten informar, escuchar, dialogar, debatir y concertar.

Fomenta el intercambio de experiencias.

Busca apoyos externos para fortalecer la institución y ayudar a estudiantes, docentes y personal administrativo.

Construye el sentido y la razón de ser del establecimiento o centro educativo que dirige.

Fuente: Guía 34, Para el Mejoramiento Institucional. MEN. (2008, p. 25)

Se aprecia que todo DD en Colombia asume un papel protagónico dentro de su comunidad educativa, debe liderar no sólo procesos académicos sino involucrarse con el crecimiento y fortalecimiento de su capital humano. Además debe atender los vínculos interinstitucionales que aporten y apoyen el desarrollo de proyectos a mediano y largo plazo. Todo esto implica un adecuado proceso de toma de decisiones, canales efectivos de comunicación, retroalimentación permanente y actualización constante.

\section{Áreas de Gestión Institucional según el Ministerio de Educación Nacional. (MEN).}

En Colombia el Ministerio de Educación Nacional ha establecido cuatro áreas de gestión de las cuales debe dar cuenta un directivo docente dentro de su cotidianidad laboral para lograr alcanzar los objetivos propuestos dentro del Proyecto Educativo Institucional (PEI), las cuales se encuentran establecidas y explicadas en la Guía 34 (MEN, 2008).

$\checkmark$ Gestión directiva: hace referencia a la forma de orientar y dirigir la institución educativa, basado en el direccionamiento estratégico, la cultura institucional, el clima institucional, gobierno escolar y relaciones con el entorno. Es decir que en este campo se determina el funcionamiento y organización general del establecimiento.

$\checkmark$ Gestión académica: se centra en el aspecto curricular de la institución, todos aquellos elementos que le permiten ofrecer una educación de calidad que satisfaga las necesidades y proyecciones de su comunidad, esto es todo lo referente con diseño curricular, prácticas pedagógicas, gestión de clases y seguimiento académico.

$\checkmark$ Gestión administrativa y financiera: dentro de esta área se ubica todo lo relacionado con las acciones realizadas para ofrecer las mejores condiciones en el desarrollo de la cotidianidad escolar, la consecución, cuidado, conservación y manejo de recursos físicos, 
pedagógicos, financieros y su adecuado manejo contable.

$\checkmark$ Gestión de la comunidad: es el aspecto relacionado con las relaciones intrainstitucionales e interinstitucionales que favorecen la convivencia, la participación, la proyección y el apoyo a proyectos de inclusión y manejo de riesgos.

\section{Manual de funciones del directivo docente}

ElMEN estableceel manual de funciones, requisitos y competencia para los cargos de directivos docentes y docentes en la Resolución 09317 del 6 de mayo de 2016 y su anexo correspondiente. Define para cada uno de los cargos de la carrera docente aspectos como: Identificación del cargo, propósito principal, funciones esenciales, conocimientos básicos, identificación de competencias comportamentales, requisitos de formación académica y experiencia.

Para la presente investigación se hace énfasis en los cargos de directivo docente con su correspondiente propósito y se requiere contar con el conocimiento de las exigencias propias del cargo según la normatividad colombiana, ya que a partir de ella y su aplicación se evalúa el desempeño de los DD.

\section{Historicidad del constructo resiliencia}

La definición de resiliencia se remonta a la década de los ' 80 cuando se asocia a la forma en que las personas reaccionaban ante los factores de riesgo, especialmente biológicos y sociales. Para tener un registro completo del proceso por el cual ha pasado el término hasta convertirse en un constructo social vinculado a los diferentes sectores académicos se presenta el recorrido histórico en la figura 3.

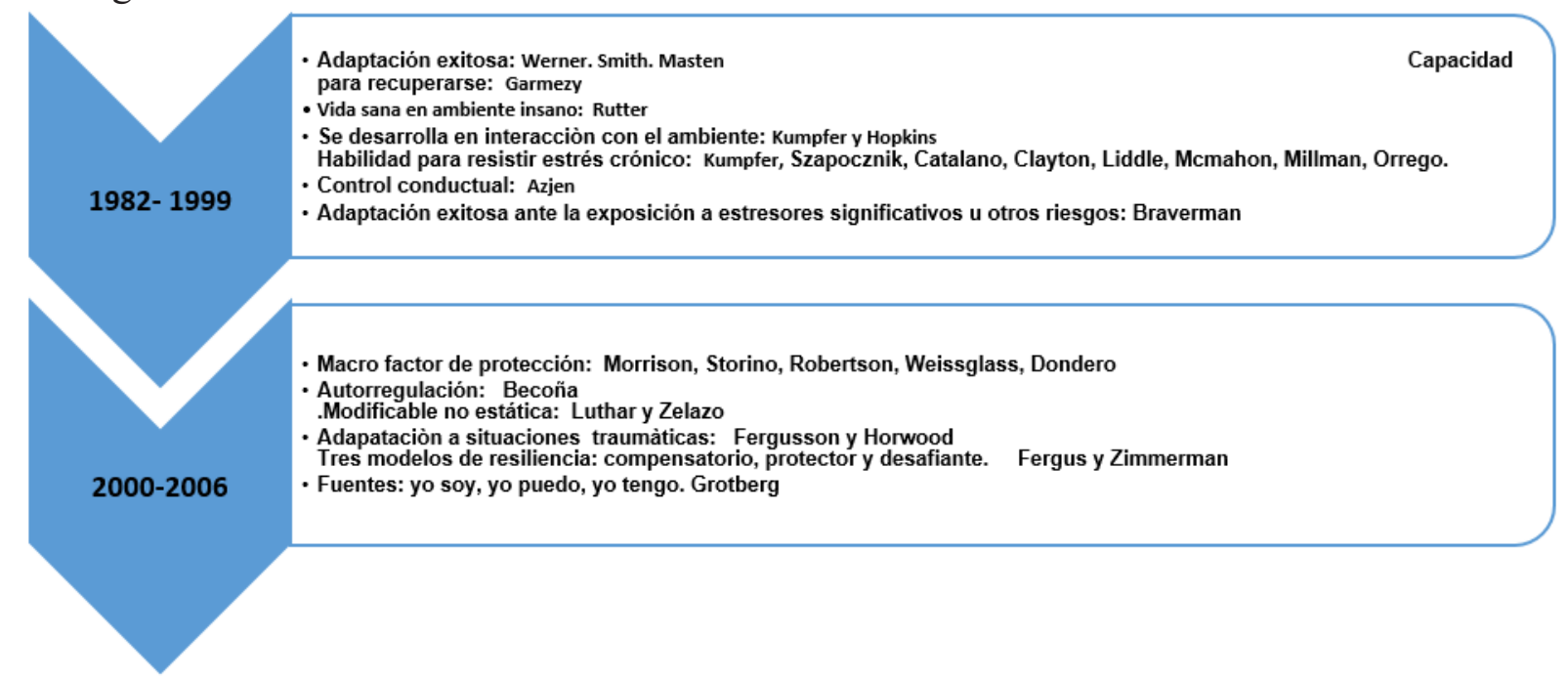

Figura 3. Retrospectiva del Constructo ResilienciaFuente: elaboración propia a partir del Manual de Resiliencia Aplicada (Puig y Rubio, 2013, p.40-43) 
Los diferentes autores coinciden en considerar la resiliencia como la capacidad de afrontar, responder y adaptarse a situaciones estresantes o de riesgo. Para el caso particular de los DD se considera la definición presentada por Grotberg, citada por Puig y Rubio (2013), "capacidad del ser humano para hacer frente a las adversidades de la vida, superarlas e inclusive, ser transformados por ellas.", como un aporte conceptual sólido que fundamenta la presente investigación. Unida al concepto propuesto por Henderson y Milstein, ya expuesto anteriormente, se convierten en el pilar teórico conceptual del constructo resiliencia.

\section{Características de la persona resiliente}

Puig y Rubio J. (2013), luego de la revisión de diversas propuestas condensan en tres elementos las características de una persona resiliente que se aprecian en la figura 4.

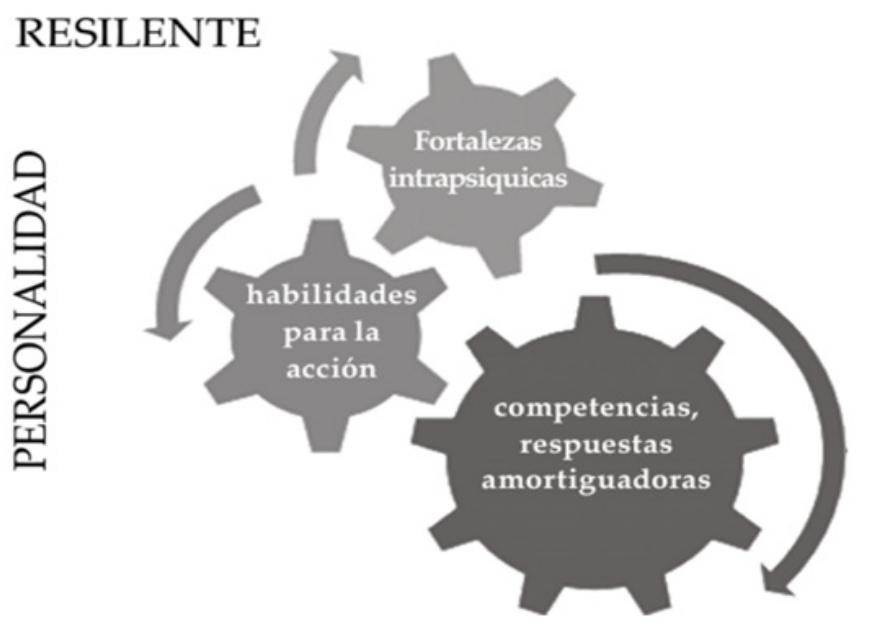

Figura 4. Características de una Persona Resiliente.

Fuente: Manual de Resiliencia Aplicada (2013.p. 99)

Fortalezas intrapsíquicas: Son factores generales o globales que forman parte de la personalidad y perspectiva de vida de cada individuo (independientes de la naturaleza de la adversidad). Por tanto se trata de características genéticas y temperamentales, que constituyen una base sobre la cual actúan los factores ambientales y sociales: empatía, autoestima, expresión y comunicación.

Habilidades para la acción: Hace referencia a la adquisición de habilidades interpersonales o sociales, de resolución de conflictos, que se orientan a la acción, y que entran en juego en la interacción: sentir afecto y expresarlo, sentido del humor, iniciativa, solidaridad, colaboración, independencia y creación.

Competencias, respuestas amortiguadoras: Sentir afecto y expresarlo. Son mecanismos 
protectores específicos: flexibilidad, adaptación y resistencia.

Al observar este esquema se infiere que la persona resiliente además de contar con características muy propias a su personalidad también se ve influenciada por el medio social, el contacto, la interacción con sus pares y la respuesta que da ante diversas situaciones desde sus reacciones hasta sus adaptaciones.

\section{Resiliencia en el contexto educativo}

El vínculo directo entre escuela y resiliencia lo expresan claramente Forés y Grané en su libro: La resiliencia en entornos socioeducativos: sentido, propuestas y experiencias (2013), donde exponen de manera categórica como la promoción de la resiliencia al interior de las comunidades educativas de los diferentes niveles, es decir desde preescolar hasta educación terciaria favorece la sana convivencia, la proactividad y la construcción de la escuela apreciativa, definida como:

Aquella que posibilita a cada uno de sus miembros utilizar sus recursos, sus valores, sus fortalezas y habilidades para afrontar dificultades y/o desafíos e innovar; también les ayuda a desplazarse desde una mirada centrada en los problemas, hacia otra que atiende a la posibilidad, les alienta a alejarse del déficit y a trabajar desde una perspectiva de afirmación de la vida. (Forés y Grané, 2013, p .15).

Es decir que se requiere incrementar ambientes escolares seguros, donde cada uno de sus miembros se sientan capaces, competentes y sobre todo valorados por sus pares, a tal punto que desarrolla habilidades y competencias académicas, sociales y vocacionales, con el objetivo de fortalecer la resiliencia y coadyuve en la disminución de factores negativos como el acoso escolar, la discriminación, la violencia y otros, que menoscaban la autoestima y las relaciones interpersonales exitosas. Los autores mencionados, afirman que: "Construir entornos educativos resilientes significa afianzar la confianza, el optimismo y la esperanza como elementos constitutivos del tejido escolar". (Forés y Grané, 2013, p. 15).

\section{Pilares de la Educación y Resiliencia del Directivo Docente}

La UNESCO en su texto La Educación encierra un tesoro (1996), establece como pilares de la Educación 4 elementos fundamentales: aprender a conocer, aprender a hacer, aprender a vivir juntos y aprender a ser. El directivo docente tiene el compromiso de fomentar dentro de la Institución Educativa que orienta estos cuatro pilares, pero no debe centrarse sólo en los estudiantes, debe lograr que trasciendan a profesores y directivos, es decir que su labor debe impregnarse no 
sólo del saber conocer (conocimiento de su rol) y del saber hacer (competencias directivas), sino también del saber ser (habilidades personales) y del saber vivir juntos (habilidades prosociales). En la tabla 4 se especifican los cuatro pilares y los requerimientos de una gestión directiva resiliente para que se cumplan de manera tácita como lo propone la UNESCO.

Tabla 4. Requerimientos de la Gestión Directiva Resiliente en concordancia con los Pilares de la Educación.

\begin{tabular}{|c|c|c|}
\hline $\begin{array}{c}\text { PILARES } \\
\text { DE LA EDUCACIÓN }\end{array}$ & $\begin{array}{l}\text { FINALIDAD. UNESCO } \\
\text { (1996, La Educación } \\
\text { encierra un tesoro, p. 36) }\end{array}$ & $\begin{array}{c}\text { REQUERIMIENTOS EN } \\
\text { LA GESTIÓN DIRECTIVA } \\
\text { RESILIENTE }\end{array}$ \\
\hline $\begin{array}{l}\text { APRENDER A } \\
\text { CONOCER }\end{array}$ & $\begin{array}{l}\text { Combinando una cultura } \\
\text { general suficientemente } \\
\text { amplia con la posibilidad de } \\
\text { profundizar los conocimientos } \\
\text { en un pequeño número de } \\
\text { materias. }\end{array}$ & $\begin{array}{l}\text { Manejo de las cuatro gestiones: } \\
\text { Directiva } \\
\text { Académica } \\
\text { Administrativa } \\
\text { Comunitaria } \\
\text { Emprendimiento } \\
\text { Manejo de emociones }\end{array}$ \\
\hline APRENDER A HACER & $\begin{array}{l}\text { a fin de adquirir no sólo } \\
\text { una calificación profesional } \\
\text { sino, más generalmente, una } \\
\text { competencia que capacite al } \\
\text { individuo para hacer frente a } \\
\text { gran número de situaciones y a } \\
\text { trabajar en equipo }\end{array}$ & $\begin{array}{l}\text { Recursividad } \\
\text { Liderazgo } \\
\text { Equidad }\end{array}$ \\
\hline $\begin{array}{c}\text { APRENDER A VIVIR } \\
\text { JUNTOS }\end{array}$ & $\begin{array}{l}\text { Desarrollando la comprensión } \\
\text { del otro y la percepción de las } \\
\text { formas de interdependencia } \\
\text {-realizar proyectos comunes } \\
\text { y prepararse para tratar } \\
\text { los conflictos- respetando } \\
\text { los valores de pluralismo, } \\
\text { comprensión mutua y paz. }\end{array}$ & $\begin{array}{l}\text { Manejo del disenso } \\
\text { Efectividad } \\
\text { Coherencia }\end{array}$ \\
\hline APRENDER A SER & $\begin{array}{l}\text {..Para que florezca mejor } \\
\text { la propia personalidad y se } \\
\text { esté en condiciones de obrar } \\
\text { con creciente capacidad de } \\
\text { autonomía, de juicio y de } \\
\text { responsabilidad personal. }\end{array}$ & $\begin{array}{l}\text { Perseverancia } \\
\text { Autoestima } \\
\text { Asertividad }\end{array}$ \\
\hline
\end{tabular}

Fuente: elaboración propia. 
Los cuatro pilares propuestos por la UNESCO son la base fundamental para la creación del Perfil del DD Resiliente, elemento básico en el diseño de la propuesta investigativa.

Por otra parte el papel del directivo docente es indiscutiblemente el de líder dentro de la comunidad educativa, es el encargado de orientar y acompañar a todos sus integrantes en el logro de los objetivos propuestos, para esta tarea requiere asumir un liderazgo efectivo, como lo expresan Day y Guy:

Comprender la naturaleza de los contextos escolares internos y externos, como están mediados por el liderazgo escolar, especialmente por el liderazgo del director, y a través de ello, como esa interacción entre contextos puede influir, positiva o negativamente, en el tejido que conforma el día a día de cualquier escuela, es clave para lograr una comprensión en profundidad de los secretos de su éxito (o su falta de éxito) a lo largo del tiempo. (2015, p. 209)

Ante esta responsabilidad se hace necesario que el directivo docente sea el estandarte que da ejemplo de entereza, tenacidad, persistencia y fortaleza, en una palabra testimonio de Resiliencia. El involucrar en la gestión directiva la resiliencia le implica vincular cuatro elementos básicos: voluntad por asumir riesgos, optimismo académico, confianza en los líderes y esperanza. (Day y Guy, 2015, p. 159). Es decir que el DD resiliente enfrenta la adversidad, las situaciones de riesgo con prevención pero no con temor, debe liderar los eventos con optimismo, brindando espacios de confianza, seguridad y equilibrio organizacional para que todos los procesos se vean permeados de serenidad evitando el caos al interior de la institución.

De igual forma se requiere cumplir con el mandato universal propuesto por la UNESCO, en la Declaración de Incheon:

"es crucial crear sistemas educativos más resilientes y con mayor capacidad de reacción ante los conflictos, las tensiones sociales y los peligros naturales, así como garantizar que se mantenga la educación durante las emergencias y las situaciones de conflicto y postconflicto”. (UNESCO, 2015, p.25).

Se observa entonces que el compromiso a nivel mundial incluye a los entes gubernamentales, el sector privado y público, la academia, la sociedad, la religión, la economía, la sociedad como corresponsables de los avances y progresos en cuanto a educación inclusiva y de calidad, de tal manera que el DD en representación de la academia, el gobierno, la familia y la sociedad debe aportar desde su labor en el establecimiento educativo con la implementación de un sistema de gestión directiva resiliente que no sólo afronte catástrofes naturales o conflictos para asegurar la 
prestación del servicio educativo sino más clave aún involucrar en su práctica diaria, en la toma de decisiones, en el manejo de relaciones personales y solución de situaciones, formas de actuar y hacer resilientes que generen confianza y estabilidad al interior de la comunidad educativa.

\section{Modelos Resilientes}

Con el transcurso del tiempo han surgido varios modelos basados en la capacidad de resiliencia para generar cambios en los individuos y comunidades, a continuación se presentan algunos de los más relevantes retomados por Puig y Rubio (2013) en el libro Manual de Resiliencia Aplicada.

El modelo elaborado por Richardson, Neiger, Jenson y Kumpfer (1990). Explica los procesos por los que puede pasar una persona que sufre una adversidad. Esta adversidad se ve amortiguada, en un principio, por los recursos internos (factores de protección) y ambientales, de los que dispone la persona. Así, si dispone de las fortalezas suficientes, será capaz de adaptarse sin mayores complicaciones y no sufrirá una ruptura significativa. Esta adaptación frente a la adversidad le devuelve a la zona de bienestar. En cambio, si los recursos de los que dispone se ven desbordados, nos encontraremos en un punto de ruptura. La superación de esa quiebra pasará por una reintegración, en la que serán determinantes, una vez más, los recursos internos y ambientales de los que disponga.

Modelo de la Casita o de Vanistendael (2004). Utiliza la figura de una casa, donde cada una de las partes representa un elemento potencial para la construcción de la resiliencia: El suelo o los cimientos simbolizan las necesidades materiales básicas, sin las cuales es imposible avanzar en la construcción; En el subsuelo encontramos la confianza básica, fruto de experiencias tempranas, en las que aparece un vínculo afectivo, elementos necesarios para afianzar la construcción de la resiliencia son todos los que forman parte de la constelación afectiva de la persona (familia, amigos, escuela); Planta baja/ primer piso, desarrollo de la capacidad para encontrar sentido y significado a lo que nos ocurre en la vida; en el segundo piso el desarrollo de aptitudes o competencias personales (sociales y profesionales) y el sentido del humor y en el último piso se ubican otras experiencias que contribuyen en la construcción de resiliencia.

Modelo de verbalizaciones de Edith Grotberg. Este modelo enfatiza que para afrontar, superar y salir fortalecido de las adversidades existen cuatro fuentes de resiliencia expresadas en cuatro verbalizaciones: "Yo tengo" en mi entorno social. "Yo soy" y "yo estoy", hablan de las fortalezas intrapsíquicas y condiciones personales. "Yo puedo", concierne a las habilidades en las relaciones con los otros. 
Modelo de Henderson y Milstein (Resiliencia en la Escuela). El modelo se centra en el campo educativo, como desde la escuela se fortalece la resiliencia; para su estructuración los autores tomaron aportes de autores como Richardson, Werner, Smith, Wolin y Bernard. Su aplicación pretende promocionar la resiliencia a partir de seis pasos. Los tres primeros están encaminados a mitigar el riesgo: Enriquecer los vínculos prosociales, fijar límites claros y firmes, y Enseñar "habilidades para la vida". Los tres pasos siguientes, se describen como elementos claves presentes en los sujetos que se sobreponen a la adversidad: brindar apoyo y afecto, Establecer y transmitir expectativas elevadas y brindar oportunidades de participación significativa.

Modelo Holístico de Gloria Gil. La propuesta se centra en seis pasos o etapas claves a saber: Conocimiento sobre resiliencia: formación específica sobre resiliencia, tanto al alumnado como al profesorado, así como al conjunto de la comunidad educativa. Indagación sobre factores de resiliencia y de no resiliencia presentes en los diferentes grupos que conforman la comunidad educativa, en el propio marco escolar y en el entorno socio-cultural donde está el centro. Análisis de los resultados mediante el mapa de resiliencia. Diseño específico por parte de la comunidad educativa del programa de promoción de resiliencia. Implementación del programa con la participación e implicación de la propia comunidad educativa y evaluación e incorporación de aprendizajes para la mejora del programa. Lo llamativo de este modelo es el hecho de involucrar la expresión "no resiliencia", donde clasifica aquellos elementos que impiden, obstaculizan y retienen el normal desarrollo de la resiliencia en los individuos.

\section{METODOLOGÍA}

El paradigma que rige el horizonte de la investigación es el Constructivista, que según Guba y Linconl (2000), ontológicamente se orienta por el relativismo, la visión con la cual el DD ejerce su labor dentro de la comunidad educativa, como se autoevalúa y genera cambios de aptitud y actitud para empoderarse en su entorno laboral. Se toma al DD como ser en proceso de crecimiento y mejoramiento continuo, desde una postura androgògica, que debe ajustarse al contexto pero también con sus comportamientos debe generar cambios en ese espacio de tiempo y lugar que ejerce su labor. En una palabra, necesita de construir y construir dentro de su accionar en el contexto laboral, profesional y social donde ejerce su labor directiva. La postura epistemológica se identifica con la transaccional subjetivista, es decir está enmarcada dentro del contacto directo entre el investigador y la población objeto de estudio.

A partir de toda la información relacionada con su forma de pensar, sentir, actuar, expectativas y la interpretación que se realice desde principios y valores educativos, disciplinares, administrativos y sociales se construye la propuesta de gestión directiva resiliente que beneficie la 
planeación y ejecución de las actividades escolares en las Instituciones Educativas. En este orden de ideas es válido tener en cuenta las bases filosóficas de la Fenomenología, toda vez que se enfoca en la forma como los directivos docentes enfrentan las situaciones de la cotidianidad y como estas les afectan en su desempeño personal, laboral, profesional y social. El objetivo fundamental de la fenomenología según Hernández Collado y Baptista (2014, p.493) es: “... explorar, describir y comprender las experiencias de las personas con respecto a un fenómeno y descubrir los elementos en común de tales vivencias", para el caso particular la presencia de la resiliencia en la gestión directiva. "La fenomenología reivindica a la subjetividad, a la ciencia del sujeto y de su experiencia desde su experiencia" (Bolio, 2012, p. 27). En atención a lo expuesto se requiere establecer las formas de ser, conocer, actuar, liderar y manejar los conflictos del grupo de directivos docentes para generar la propuesta que cualifique los procesos de gestión directiva, académica, administrativa y comunitaria.

De igual forma al contemplar el comportamiento, el actuar y el asumir del directivo docente se hace necesario interpretar cada una de sus acciones, sus pensamientos y posturas ante los retos que la dirección de los centros educativos le impone, por lo tanto la investigación se encauza dentro del horizonte metodológico de la Hermenéutica, que viene de Hermeneuein (interpretar) y significa la técnica y el arte de la interpretación textual. Como lo expresa Grondin (2008, p.40) "entendida como el arte de la interpretación de las manifestaciones vitales fijadas por escrito”. Para lograr la interpretación y comprensión entran en juego diversos elementos, como son la experiencia, pensamientos, nociones, ideas y conceptos.

El tipo de investigación a desarrollar es Proyectiva a la cual se refiere Hurtado de Barrera, como aquella que "trasciende el campo de "cómo son" las cosas, para entrar en el "cómo podrían o cómo deberían ser" en términos de necesidades, preferencias o decisiones de ciertos grupos humanos" (2012, p. 559). La misma autora define las características de este tipo de investigación: intenta proponer soluciones a una situación determinada a partir de un proceso de investigación; implica pasar por los estadios explorar, describir, comparar, explicar, predecir y proponer alternativas de cambio, más no necesariamente ejecutar la propuesta; los proyectos pueden ser de tipo económico, social, educativo, tecnológico, artístico, entre otros; la investigación proyectiva parte de la identificación de un evento a modificar, y el diagnóstico descriptivo en el cual se inicia la investigación se hace con base en ese evento a modificar y el término proyectivo está referido a proyecto en cuanto a propuesta. (Hurtado de Barrera, 2012, p.248). Las fases del proceso investigativo desarrolladas son las propuestas por la autora en mención: exploratoria, descriptiva, analítica, comparativa y explicativa; predictiva; proyectiva; interactiva y evaluativa. 
Es necesario precisar también el tipo de abordaje, es decir la forma como el investigador va a desarrollar estas fases. Un primer criterio a tener en cuenta es el grado de estructuración o flexibilidad con la que el investigador se acerca al evento de estudio. Según Hurtado de Barrera (2012, p. 289) existen tres posturas, a saber: caológica, cosmológica y complementariedad. La primera es flexible, inestructurada, abierta y recurre a técnicas e instrumentos como la entrevista, la observación, registros y diarios de campo, el uso de categorías y la triangulación; la segunda es cerrada, localizada y estructurada, por lo tanto se usan técnicas e instrumentos como el cuestionario de pregunta cerrada, las escalas y entrevistas estructuradas y se recurre al análisis estadístico; la tercera permite la presencia de las dos primeras, indistintamente del orden en que se den, se puede iniciar desde un abordaje caólogico y pasar a uno cosmológico y viceversa. Para el caso que nos ocupa se orienta por el principio de la Complementariedad, porque como lo expresa Hurtado de Barrera, "los abordajes caológico y cosmológico no son de ninguna manera excluyentes; por el contrario se necesitan el uno al otro" (2012, p. 301).

Otro criterio a contemplar es la participación de los investigados durante la planeación y ejecución de la investigación. Para el caso particular se clasifica como exógeno, porque es generado y guiado por el investigador permanentemente, además las unidades de estudio se vinculan sólo en la fase de recolección de información donde de manera espontánea, sin ninguna prevención expresan su forma de sentir, pensar, actuar y expectativas frente al fenómeno de estudio. Por otra parte, existe el criterio relacionado con la perspectiva desde la cual se realiza la interpretación del evento, frente a esta situación toda investigación se puede catalogar como Etic o Emic.

La presente investigación se categoriza con una visión Emic, es decir centrada en los investigados o unidades de estudio, la forma como ellos perciben, asumen y se motivan hacia la propuesta de gestión directiva resiliente.

El proceso investigativo para la recolección de datos se orienta bajo los principios de fuente de campo, porque se toma como base la información que proporciona la población directamente relacionada con el fenómeno, su contexto, su sentir, su experiencia, sus expectativas y aportes. Según Hurtado de Barrera, “...el investigador obtiene la información relacionada con su estudio a partir de fuentes vivas, o materiales, en su contexto natural o habitual. Las fuentes vivas pueden ser personas, plantas, animales...” (2012, p. 694). El momento es transeccional contemporáneo, porque se realiza en el tiempo y el espacio directo de la ejecución de la investigación.

La población base de la investigación son los directivos docentes vinculados a la Secretaria de Educación del municipio de Bucaramanga (SEB), conformado por rectores, coordinadores y 
directores rurales.

Tabla 6: Planta de personal directivo docente municipio de Bucaramanga.

\begin{tabular}{|c|r|r|}
\hline CARGO & \multicolumn{1}{|c|}{ NÚMERO } & PORCENTAJE \\
\hline RECTORES & 35 & $22,43 \%$ \\
\hline DIRECTIVOS RURALES & 3 & $1,92 \%$ \\
\hline COORDINADORES & 118 & $75,64 \%$ \\
\hline TOTAL & 156 & $100 \%$ \\
\hline
\end{tabular}

Fuente: Elaboración propia a partir de Resolución no.1195 del 16 de marzo de 2018, Secretaria de Educación de Bucaramanga. (SEB)

Como se aprecia el número total de población es de 156 directivos docentes, donde se involucran las diferentes asignaciones de cargos y/o funciones de estos funcionarios de la educación objeto de la investigación.

\section{RESULTADOS OBTENIDOS EN LA INVESTIGACIÓN.}

\section{A nivel de Directivos Docentes en calidad de Coordinadores}

En cuanto a estas unidades de estudio se resalta la ubicación de los términos o conceptos de acuerdo al nivel de repitencia o relevancia, se observa que se presentan tres palabras claves para el estudio: educación, estudiantes y situaciones, lo que deja entrever que son las situaciones con estudiantes las que ameritan mayor atención de parte de los Directivos Docentes en calidad de coordinadores. Esto determina el nivel de atención que requieren las funciones y actividades que realizan diariamente. En la gráfica 26 se detallan otras expresiones como coordinación, fortalezas, profesional, asistencia, responsabilidad, conflicto, convivencia, organización, resiliencia que confluyen de manera más directa y cercana a las tres expresiones ya mencionadas, ubicadas en primer nivel.

También se considera importante tener en cuenta que expresiones como habilidades, colaboración, organizado, inconvenientes, compañeros, facilidad y habilidad se encuentran un tanto más distantes pero ejercen su rol dentro de las situaciones educativas con estudiantes. Dentro de este grupo se resalta la aparición de los términos compañeros y dificultades lo cual permite divisar que las relaciones entre pares suelen generar tensión o atención especial.

Otra mirada que se realiza es la ubicación específica de las expresiones: al centro las de mayor relevancia como ya se expuso, pero a su vez en la parte inferior dando base, fundamento o soporte se ubican: coordinación, fortalezas, importante y profesional. Estas cuentan con expresiones que asemejan las columnas como son responsabilidad e instituciones que se enfrentan de manera directa 
con el conflicto. En una posición mitigante se observa la resiliencia, funciones, organización y asistencia, porque se ubican estratégicamente alrededor de Situaciones Educativas con Estudiantes.

Para finalizar es interesante ver como de la expresión Situaciones se derivan términos claves para su solución como son: habilidad, determinado y convivencia. Se infiere que para solucionar las situaciones que afrontan los coordinadores requieren de habilidades especiales para el manejo de la sana convivencia. (Ver figura 8)

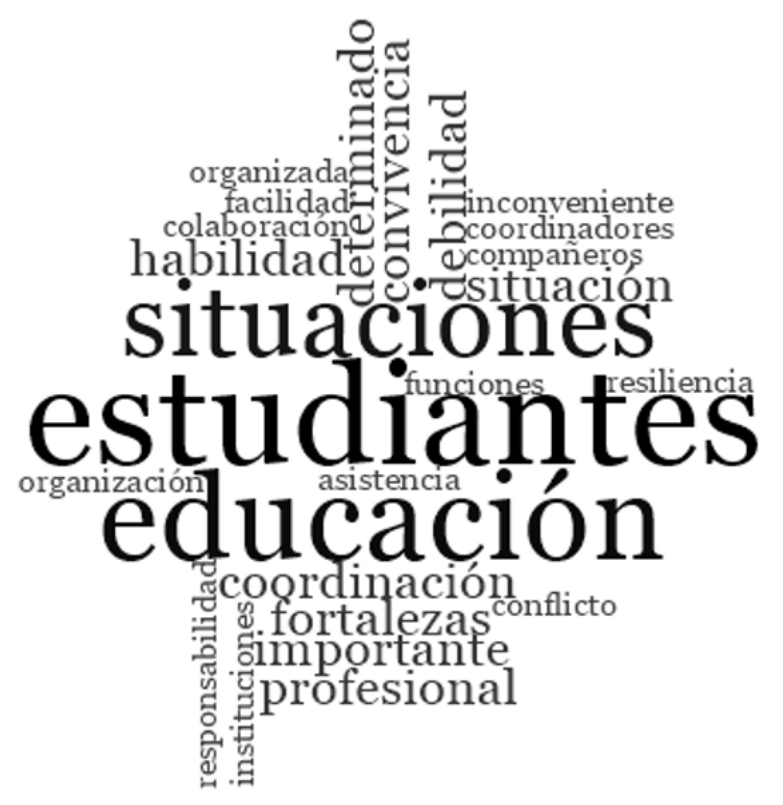

Figura 8.Nube de palabras en orden de relevancia otorgada por Directivo Docente Coordinador.

Fuente: software Nvivo ${ }^{\circledR}$

En un rasgo relevante se convierten las conexiones que emergen entre los diferentes nodos como se puede apreciar en la figura 9, porque ubicados de forma equidistante se observa la conformación de cinco triadas que dan las pautas sobre que ejes debe girar la Propuesta Investigativa:

$\checkmark$ Primera Triada: definición de resiliencia, fortalezas y debilidades, se infiere que dependiendo del acercamiento al constructo resiliencia los coordinadores cuentan con unas fortalezas y unas debilidades que identifican como favorables o desfavorables en el manejo de las situaciones difíciles de la cotidianidad.

$\checkmark$ Segunda triada: situaciones tensionantes, aportes a la investigación y aportes de la resiliencia a la labor. Se encuentra el vínculo directo entre estos tres nodos, puesto que para enfrentar las situaciones tensionantes los coordinadores sienten que la investigación y la resiliencia son elementos fundamentales que les proporcionan elementos válidos, habilidades y estrategias de intervención efectivas. 
$\checkmark$ Tercera triada: habilidades que enriquecen el desempeño, debilidades y situaciones tensionantes. Se infiere que estos tres nodos se vinculan de manera directa toda vez que las habilidades personales, laborales, profesionales y sociales son el insumo fundamental para afrontar las situaciones tensionantes y a su vez son el elemento minimizador de las debilidades que puedan tener los coordinadores en el manejo asertivo de los conflictos que se presentan a menor o gran escala.

$\checkmark$ Cuarta triada: funciones, definición de resiliencia e interés por aplicar el modelo de gestión. En esta triada se vinculan tres nodos que le dan el soporte a la investigación puesto que la propuesta parte de las funciones que por normatividad colombiana deben cumplir los coordinadores, pero la meta es lograr fusionar este elemento legal que tiene relación con el saber hacer y vincularlo con dos nodos que puntualizan en el saber ser, en la parte del desarrollo humano desde su sentir, actuar y pensar.

$\checkmark$ Quinta triada: aportes de la resiliencia a la labor, fortalezas y parámetros en la solución de situaciones. En esta triada que emerge se identifica el vínculo intrínseco entre la resiliencia con las fortalezas que debe contemplar el perfil del Directivo Docente para aplicar o identificar los parámetros a tener en cuenta en la solución de una situación difícil o manejo de situaciones tensionantes en la cotidianidad escolar.

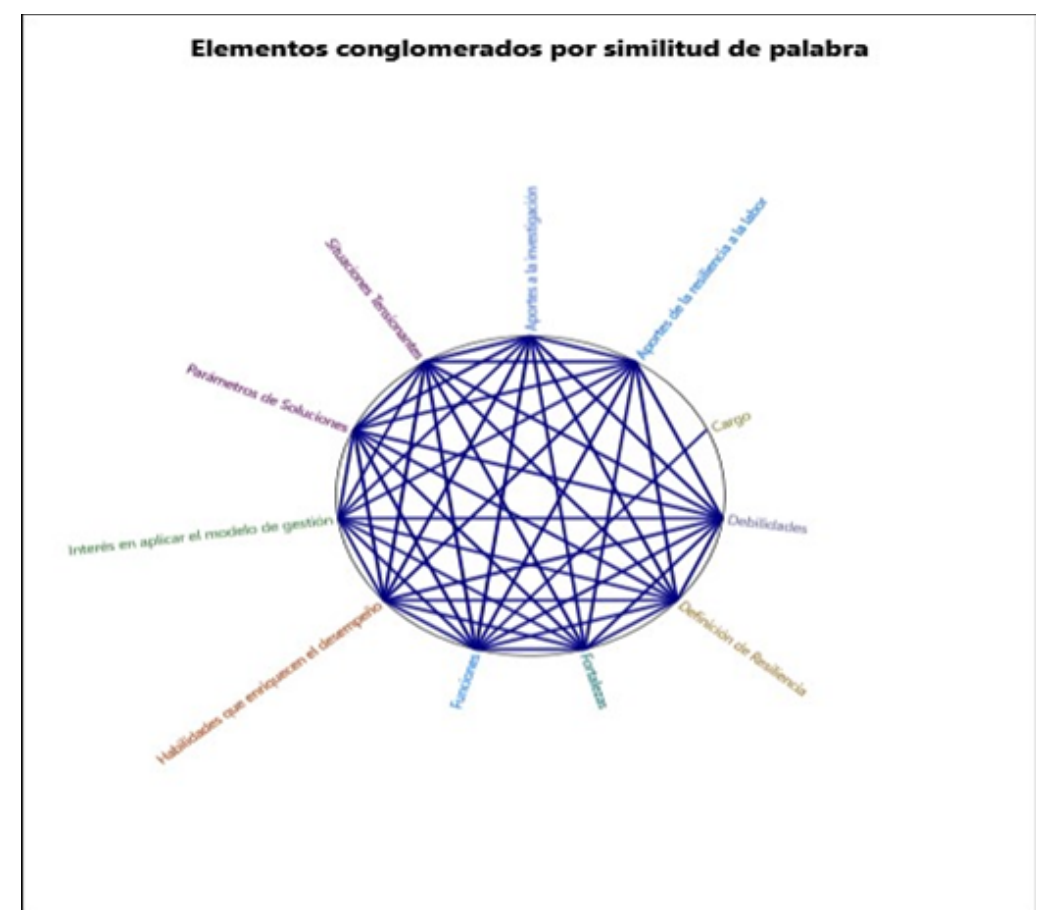

Figura 8. Elementos conglomerados por similitud de palabra en Entrevista a Directivo Docente Coordinador Fuente: software Nvivo 


\section{A nivel de profesionales en calidad de expertos}

Al realizar la clasificación y análisis de la información recolectada con los expertos sobresalen en la nube de palabras por su mayor porcentaje de repitencia y presencia los términos Habilidades y Propuesta, que se ubican en el centro. Seguidamente, en un porcentaje menor y en nivel ascendente las palabras: persona, directiva y docente. En el mismo porcentaje pero en nivel descendente se ubican los términos estrés, gestión, directivos. Lo cual es consecuente con los términos centrales porque las habilidades van directamente relacionadas con la persona directiva y docente; y la propuesta está vinculada con mitigar el estrés que afronta en la gestión los directivos. Además en la parte superior a manera de proyección y con menor recurrencia se ubican otras expresiones como: resiliencia, competencias, relación, proceso, potenciar, estrategia, inherente y estructura. Todas ellas relacionadas con las habilidades del Directivo Docente Resiliente. En la parte inferior a manera de soporte se encuentran las palabras: información, capacidad, personal, cognitiva, afrontamiento, resultados, comunicación, características personales, resiliente, atención y experiencia.

Teniendo en cuenta lo anterior se deduce que en la construcción de la propuesta investigativa se debe dar mayor relevancia a las habilidades del Directivo Docente, tener como fundamento la comunicación y el afrontamiento de situaciones, así como brindar una estructura que potencie y genere competencias resilientes. (Ver figura 9).

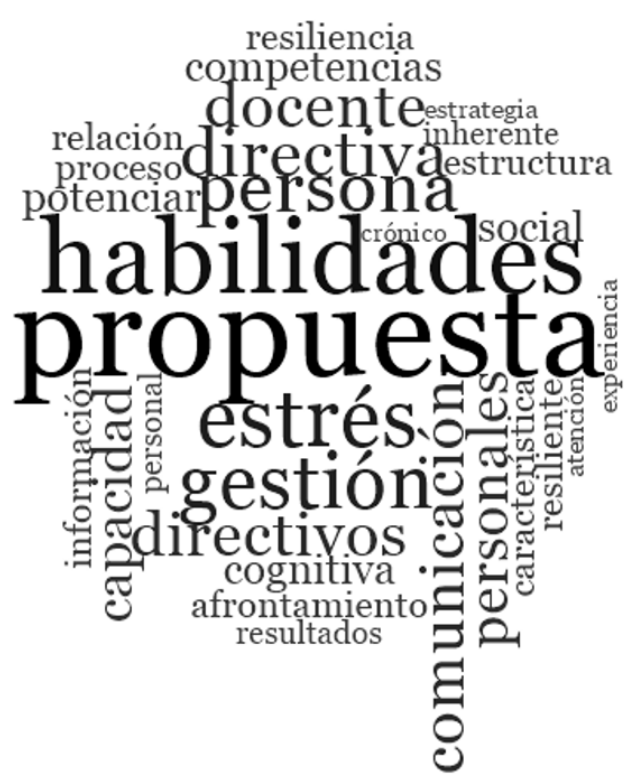

Figura 9. Nube de palabras en orden de relevancia otorgada por los expertos.

Fuente: software Nvivo® 
Los expertos dan luces sobre elementos a tener en cuenta en el momento de construir la propuesta investigativa, especialmente cuando enuncian que debe estar comprendida por dos aspectos: habilidades personales y gerenciales. Al igual que tener en cuenta las estrategias de afrontamiento, manejo del tiempo, procesos de planificación y manejo de la incertidumbre y los imprevistos. Además, los expertos coinciden que la mayor tensión que afrontan los DD tiene que ver con la comunicación, las relaciones interpersonales con estudiantes, padres de familia, administrativos y la comunidad en general. La forma como se reciben los mensajes o directrices porque en ocasiones se distorsiona o se entiende de una manera totalmente diferente. Consideran que el Directivo Docente por estar al pendiente de variedad de funciones se descuida en su capacitación y actualización lo cual genera inconvenientes en el momento de direccionar la gestión académica. Se deduce entonces que la propuesta investigativa debe contemplar la comunicación y la formación académica como factores fundamentales. Es importante el aporte que hacen los expertos al perfil del DD, al respecto enuncian una serie de habilidades: capacidad cognitiva que favorece la atención, concentración y memoria, agilidad mental, solución de situaciones, De igual forma contemplan la asertividad, la capacidad de comunicarse, el buen trato, la empatía, conocimiento de las situaciones, liderazgo y capacidad de escucha. Al momento de construir el Perfil del Directivo Docente Resiliente serán un insumo fundamental.

\section{A nivel de Directivo Docente en calidad de rectores}

A continuación se presentan los resultados que tienen mayor impacto en la Propuesta investigativa.

Una capacidad que es importante determinar es la perseverancia y la constancia del Directivo Docente Rector cuando se responsabiliza ante un proyecto o simplemente sus labores cotidianas. Ante este cuestionamiento se evidencia que los rectores se ubican en el orden de los siguientes rangos: frecuentemente (47.4\%), muy frecuentemente (34.2\%) y ocasionalmente (18.4\%). El hecho de no tener presencia en los rangos nunca y raramente es bastante positivo porque se puede concluir que los rectores son comprometidos y persistentes con los proyectos que emprenden.

Los encuestados afirman que frecuentemente (47.4\%), muy frecuentemente (44.7\%) y ocasionalmente $(7.9 \%)$ resuelven las situaciones que les generan tensión, lo cual permite afirmar que efectivamente quien dirige la comunidad educativa está constantemente expuesto a estrés y requiere un adecuado manejo de las emociones para mantener un equilibrio emocional.

Es importante tener la claridad que el rector cuente con la capacitación, manejo y experticia del cargo que ejerce. Ante este cuestionamiento los encuestados afirman en mayor porcentaje 
que frecuentemente (39.5\%) y ocasionalmente reciben capacitación (36.8\%), en tercer lugar se ubica el porcentaje asignado a raramente $(10.5 \%)$, seguido de nunca $(7.9 \%)$ y por último muy frecuentemente (5.3\%). Estos tres últimos porcentajes sin ser altos llama la atención que haya rectores que manifiesten no ser capacitados oportunamente lo cual implica que se realicen procesos al interior de algunas Instituciones educativas sin la debida orientación lo cual puede generar pérdida de tiempo, desgaste del personal y confusión ante la comunidad educativa.

Un rector requiere ejercer el rol de líder de manera directa para lograr direccionar su comunidad hacía el logro de las metas propuestas. En esta oportunidad los rectores encuestados afirman en un alto porcentaje muy frecuentemente se consideran líderes dentro de la comunidad educativa con todo lo que este rol exige $(63,2 \%)$, seguido en porcentaje del rango frecuentemente $(34,2 \%)$. Existe presencia mínima de porcentaje en la opción de raramente (2.6\%), lo cual así sea bajo, indica que sin ser representativo si existen comunidades educativas donde no cuentan con un rector que sea líder. Preocupante situación porque se generan cuestionamientos como: ante la ausencia del rector líder, ¿quién está ejerciendo este liderazgo? ; ¿El ente nominador, para este caso la Secretaría de Educación de Bucaramanga, tiene conocimiento de esta situación?; y si es así, está realizando algún tipo de acompañamiento o asesoría?

En la cotidianidad el rector de una Institución Educativa se relaciona con diferentes miembros de la comunidad con los cuales enfrenta situaciones agradables o no, es en ese momento cuando se presentan tensiones o conflictos. Para la investigación en curso es importante dejar en claro cuáles relaciones le generan mayor tensión y ante este cuestionamiento se aprecia que todas las opciones obtuvieron representación porcentual y el orden de mayor a menor fue: relación con docentes o subalternos, cumplimiento de requerimientos con la Secretaría de Educación, manejo casos con estudiantes, atención a Padres y otros.

Para finalizar es importante tener claro la disponibilidad de la población objeto de estudio de aplicar la propuesta investigativa porque esta es la verdadera razón de la investigación y al respecto se encuentra un alto porcentaje que está dispuesto a replicarla en el interior de las Instituciones Educativas. Este aspecto es bastante positivo porque se ha motivado a tal grado a la población que ya está a la expectativa para recibir y aplicar en un $78.9 \%$ el producto final. Las razones por las cuales están motivados es porque consideran que se mejora la gestión personal del DD, se aportará en la mejora del clima laboral y la convivencia de toda la comunidad educativa. 


\section{Discusión e interpretación de los resultados}

Una vez realizado el análisis de los resultados obtenidos en cada una de las técnicas aplicadas se considera oportuno condensar los hallazgos encontrados en torno a los objetivos específicos donde confluye lo aportado desde la teoría y desde cada uno de las unidades de estudio para visibilizar los elementos afines o discrepancias que permitan enriquecer la fundamentación de la Propuesta investigativa.

\section{Elementos de la Propuesta Investigativa}

Una vez se realiza la lectura de los diferentes aportes de las fuentes al Objetivo investigativo relacionado con los elementos que deben constituir la Propuesta investigativa se categorizan en cuatro grandes bloques: a nivel personal, nivel profesional, nivel laboral y nivel social. A los cuales el investigador debe darle solidez y fundamentación para que formen parte del entramado investigativo (ver tabla 7).

Tabla 7. Elementos que deben constituir la propuesta de gestión directiva resiliente para los directivos docentes.

\begin{tabular}{|c|c|}
\hline $\begin{array}{l}\text { ELEMENTOS A NIVEL PERSONAL } \\
\checkmark \quad \text { Nuevas formas de comprender y de actuar. } \\
\checkmark \quad \text { Ontológicamente, concebir el hombre como ser } \\
\text { cambiante y dinámico. } \\
\checkmark \quad \text { Holológicamente, el ser debe permanecer } \\
\text { inmerso en el sistema de formación. } \\
\checkmark \quad \text { Androgógicamente: no debe dar el ciclo por } \\
\text { finalizado, todo lo contrario debe ser consciente } \\
\text { que su experiencia enriquece a otros y él se } \\
\text { beneficia cuando amplía sus horizontes y actúa } \\
\text { de forma resiliente. }\end{array}$ & 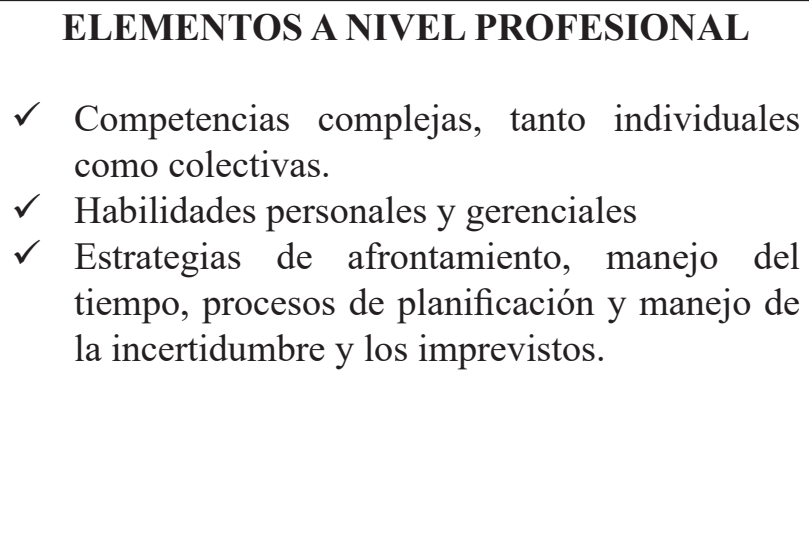 \\
\hline ELEMENTOS A NIVEL LABORAL & ELEMENTOS A NIVEL SOCIAL \\
\hline $\begin{array}{l}\checkmark \text { El involucrar en la gestión directiva la resiliencia } \\
\text { le implica vincular cuatro elementos básicos: } \\
\text { voluntad por asumir riesgos, optimismo } \\
\text { académico, confianza en los líderes y esperanza. } \\
\text { (Day et al, 2015, p. 159). } \\
\checkmark \text { Inserción del liderazgo transformacional } \\
\checkmark \\
\text { Conocimiento y apropiación de las funciones } \\
\text { de los coordinadores según la normatividad } \\
\text { vigente. }\end{array}$ & $\begin{array}{l}\checkmark \text { Mantener un nivel de motivación, satisfacción } \\
\text { y capacitación acorde con su desempeño dentro } \\
\text { de la comunidad para que en el momento que } \\
\text { surge una eventualidad o situación de riesgo } \\
\text { se sienta lo suficientemente empoderado y } \\
\text { reaccione de forma resiliente. } \\
\checkmark \text { Recurrir al diálogo, el escuchar, el indagar, el } \\
\text { actuar, el analizar y delegar. } \\
\checkmark \quad \text { Fortalecer la tenacidad; aceptación positiva del } \\
\text { cambio; control y las influencias espirituales. }\end{array}$ \\
\hline
\end{tabular}

Fuente: elaboración propia 


\section{Panorama del directivo docente y normatividad}

$\checkmark$ El directivo docente debe dar cuenta de una función administrativa, pedagógica y social. Toda vez que debe direccionar los procesos de planificación, organización y control, a su vez que debe procurar por mantener un buen ambiente laboral y dar sus aportes en el campo pedagógico.

$\checkmark$ La comunicación y relaciones interpersonales son las que producen mayor tensión y agotamiento en el Directivo Docente. La alarma se enciende porque los conflictos se presentan con padres de familia, estudiantes, profesores, es decir que con la gran parte de miembros de la comunidad con quienes interactúan día a día.

$\checkmark$ El cumplimiento de múltiples funciones y tareas a nivel de las cuatro áreas de gestión, evidencia en ellos una sobrecarga laboral que impide cubrir otros aspectos como es la capacitación personal y fortalecimiento profesional que enriquezcan el campo pedagógico al interior de sus instituciones.

$\checkmark$ El Directivo Docente requiere alejarse de la gestión netamente administrativa para asumir una gestión educativa que le permita ser más cercano a su comunidad, le otorgue mayor protagonismo en los diversos procesos sin ser el quien los ejecute en su totalidad sino quien los oriente, regule y evalúe.

$\checkmark$ Se dejan de manifiesto debilidades a nivel personal, laboral y profesional que inciden en el ámbito social, lo cual es bastante negativo porque quien lidera debe dar ejemplo de manejo de emociones, ansiedad, temperamento y organización.

$\checkmark$ La propuesta investigativa es un aporte fundamental para contrarrestar enfermedades de tipo laboral como son el estrés, el Síndrome de Agotamiento Profesional (SAP) y el síndrome de Burnout.

\section{Perfil del Directivo Docente Resiliente}

La información recolectada en cuanto al Perfil del Directivo Docente es bastante precisa y coherente con el fin máximo de la resiliencia: generar ambientes sanos al interior de las personas que proyecten serenidad y proactividad en sus comunidades. La información recolectada sobre las habilidades requeridas se han agrupado en cuatro dimensiones que están en consonancia con los elementos de la propuesta: dimensión personal, dimensión profesional, dimensión laboral y dimensión social. (Ver tabla 8). 
Tabla 8. Aportes al Perfil del Directivo Docente por las diferentes fuentes

\begin{tabular}{|c|c|}
\hline $\begin{array}{ll} & \text { Dimensión personal } \\
\checkmark & \text { Capacidad cognitiva que favorece la } \\
& \text { atención, concentración y memoria. } \\
\checkmark & \text { Agilidad mental } \\
\checkmark & \text { Suelen ser abiertos y espontáneos ante las } \\
& \text { diversas situaciones. } \\
\checkmark & \text { Motivación. } \\
\checkmark & \text { Autoestima. } \\
\checkmark & \text { Inteligencia emocional. }\end{array}$ & $\begin{array}{ll}\checkmark & \text { Toma la iniciativa, se ánima y se muestra } \\
& \text { emprendedor ante su comunidad. } \\
\checkmark & \text { Actúan de manera coherente } \\
\checkmark & \text { Responsabilidad. } \\
\checkmark & \text { Formación constante. } \\
\checkmark & \text { Toma de decisiones. } \\
\checkmark & \text { Manejo del tiempo. }\end{array}$ \\
\hline \begin{tabular}{ll} 
& \multicolumn{1}{c}{ Dimensión laboral } \\
$\checkmark$ & Son comprometidos y persistentes con los \\
& proyectos que emprenden. \\
$\checkmark$ & realiza gestión para conseguir los recursos \\
& necesarios. \\
$\checkmark$ & Reconocer el saber del otro. \\
$\checkmark$ & Creatividad. \\
$\checkmark$ & Trabajo en equipo. \\
$\checkmark$ & Organización. \\
$\checkmark$ & Innovación pedagógica. \\
$\checkmark$ & Saber delegar funciones. \\
$\checkmark$ & Perfecto equilibrio
\end{tabular} & $\begin{aligned} & \text { Dimensión Social } \\
& \checkmark \text { La asertividad, la capacidad de } \\
& \text { comunicarse, el buen trato, la empatía, } \\
& \text { conocimiento de las situaciones, liderazgo } \\
& \text { y capacidad de escucha. } \\
& \checkmark \quad \text { Procura ser justo y equitativo para no } \\
& \text { generar conflictos } \\
& \checkmark \quad \text { Procurar el bienestar de la comunidad } \\
& \checkmark \quad \text { (profesores, estudiantes, padres de familia) } \\
& \checkmark \text { Capacidad de adaptación. } \\
& \checkmark \text { Buenas relaciones personales. } \\
& \checkmark \text { Atención al público. } \\
& \checkmark \text { Empatía. }\end{aligned}$ \\
\hline
\end{tabular}

Fuente: elaboración propia

\section{La resiliencia, eje dinamizador en la gestión directiva}

Se observa que todos los actores consideran la resiliencia como la capacidad del ser humano de afrontar las situaciones adversas y no dejarse minimizar en su actuar sino todo lo contrario asumir de forma directa, creativa y recursiva los eventos para encontrar las mejores soluciones y el máximo desempeño del Directivo Docente que lleve las instituciones Educativas a salir adelante y ofrecer cada día un ambiente sano y propicio para el proceso de enseñanza aprendizaje. A continuación se presenta el listado de expresiones y aportes a tener en cuenta:

$\checkmark$ Resiliencia es "capacidad del ser humano para hacer frente a las adversidades de la vida, superarlas e inclusive, ser transformados por ellas.", Edith Grotberg.

$\checkmark$ Disponibilidad de la población objeto de estudio de aplicar la propuesta investigativa: tiene relación directa entre la aplicación de la Propuesta Investigativa y la mejora en la gestión personal del Directivo Docente Rector, vinculan directamente la institucionalización 
de la Propuesta con los cambios positivos en el clima laboral y convivencia de toda la comunidad educativa.

$\checkmark$ La promoción de la resiliencia desde preescolar hasta educación terciaria favorece la sana convivencia, la proactividad y la construcción de la escuela apreciativa.

$\checkmark$ Se vislumbra la Propuesta Directiva Resiliente como una estrategia eficaz en el manejo de las relaciones interpersonales que va a fortalecer su desempeño dentro de las cuatro áreas de gestión y por lo tanto minizarà los conflictos y tensiones que enfrentan.

$\checkmark$ "es crucial crear sistemas educativos más resilientes y con mayor capacidad de reacción ante los conflictos, las tensiones sociales y los peligros naturales, así como garantizar que se mantenga la educación durante las emergencias y las situaciones de conflicto y postconflicto". Declaración de Incheon

$\checkmark$ Los coordinadores establecen una relación tríadica entres definición de resiliencia, fortalezas y debilidades.

$\checkmark$ Una segunda relación tríadica que queda de manifiesto es: situaciones tensionantes, aportes a la investigación y aportes de la resiliencia a la labor.

$\checkmark$ Identificación de los cinco ejes sobre los cuales se construye y potencia la creatividad y la resiliencia: fortalecimiento personal, análisis de factores de riesgo, resiliencia: elaboración personal y social, manejo de estados emocionales, proyecto de vida y toma de decisiones (Quiñonez R. 2006, p. 199).

\section{Consideraciones finales}

Dentro del proceso investigativo se han abordado a la fecha lo concerniente los elementos de los modelos de gestión que contempla la normatividad colombiana, latinoamericana y europea. De igual forma se han evidenciado las competencias que debe asumir, evidenciar y aplicar el directivo docente según el MEN. Luego de la revisión teórica se tienen en cuenta para el Diseño del Propuesta de Gestión Directiva Resiliente algunas premisas como:

$\checkmark$ Se requiere establecer el rol a asumir por el DD: gerente, líder, educador, administrador, evaluador o gestor de políticas del Estado.

$\checkmark$ Definir el tipo de autoridad que va a ejercer dentro de la comunidad educativa.

$\checkmark$ Además de contar con la visión administrativa que favorece el manejo resiliente de las situaciones e identificar los canales de comunicación que favorecen la consolidación de un estilo directivo resiliente.

$\checkmark$ Se confirma que la Resiliencia conlleva un efecto tranquilizador y emancipador a los diferentes agentes educativos, puesto que toda vez que vinculen actitudes, frases y acciones resilientes en su cotidianidad lograrán disminuir la carga negativa que expresiones agresivas, discriminadoras o generadoras de conflicto que se presentan, y si 
estos comportamientos resilientes provienen de los directivos que son vistos como líderes y ejemplo al interior del contexto educativo es mucho más productivo su efecto positivo y propagador de ambientes educativos apreciativos.

$\checkmark$ Las Implicaciones de una Propuesta de Gestión Directiva Resiliente son:

Ontológicamente, concebir el hombre como ser cambiante, dinámico, dispuesto mejorar sus prácticas personales, laborales y sociales. Holológicamente, el ser debe permanecer inmerso en el sistema de formación, porque cada día se aprende y se enseña, cada día se forma una mejor persona a partir del aporte individual y colectivo, su actitud debe ser de disponibilidad hacía el conocimiento que siempre busca mejorar las condiciones de vida de la humanidad. En cuanto a la formación, todo ser humano está siempre ávido de conocimiento, en búsqueda de cualificar sus niveles de vida y requiere, en este caso el directivo docente mejorar la respuesta que da ante situaciones adversas, conflictos con sus pares, padres de familia, profesores y estudiantes. Androgógicamente, todo directivo docente está en edad adulta y ya ha recibido información, orientación, instrucción, capacitación, educación y formación pero no debe dar el ciclo por finalizado, todo lo contrario debe ser consciente que su experiencia enriquece a otros y él se beneficia cuando amplía sus horizontes y actúa de forma resiliente.

\section{REFERENCIAS BIBLIOGRÁFICAS}

- Bolio, Antonio Paoli (2012). Husserl y la fenomenología trascendental: Perspectivas del sujeto en las ciencias del siglo XX. REencuentro. Análisis de Problemas Universitarios, (65), 20-29. [Fecha de consulta 15 de abril de 2020]. ISSN: 0188-168X. Disponible en: https://www.redalyc.org/articulo.oa?id=340/34024824004

- Borden M. (2006). Directores de Escuela en América Latina y el Caribe: ¿Líderes del Cambio o Sujetos a Cambio? Recuperado de: https://docplayer.es/5316499-Directoresde-escuela-en-america-latina-y-el-caribe-lideres-del-cambio-o-sujetos-a-cambioallison-m-borden-1.html

- Borden M. (2009). El liderazgo del director escolar para el mejoramiento de la calidad educativa. Recuperado de: http://www.empresariosporlaeducacion.org/sites/default/ files/11_el_liderazgo_del_director_escolar_octubre_2009.pdf

- Cerquera, C. Ara y Pabón-Poches, Daysy. (2014). Modelo de intervención psicológica en resiliencia para cuidadores informales de pacientes con Alzheimer * Psychological intervention model for informal caregivers of patients with Alzheimer. Tesis doctoral. diversitas. 11. 181-192. 10.15332/s1794-9998.2015.0002.01.

- Day, C., y Gu, Q. (2015). Educadores resilientes, escuelas resilientes: construir y sostener la calidad educativa en tiempos difíciles. Recuperado de: https://books. google.com.co/books?id=_PakDwAAQBAJ\&printsec=frontcover\&dq=Educad 
ores + resilientes, + escuelas + resilientes $:+$ construir $+y+$ sostener + la + calidad + educ ativa + en + tiempos + dif\%C3\%ADciles $\&$ hl $=$ es-419\&sa $=$ X\&ved $=0$ ahUKEwitkpT0-noAhWCc98KHdTrDEwQ6AEIKDAA\#v=onepage \&q=Educadores\%20 resilientes $\% 2 \mathrm{C} \% 20$ escuelas $\% 20$ resilientes $\% 3 \mathrm{~A} \% 20$ construir\%20y\%20sostener $\% 20$ la\%20calidad\%20educativa\%20en\%20tiempos\%20dif\%C3\%ADciles\&f=false

- Egido Gálvez, M. (2006). EL DIRECTOR ESCOLAR: MODELOS TEÓRICOS, MODELOS POLÍTICOS. Avances en Supervisión Educativa, (4). Consultado de https:// avances.adide.org/index.php/ase/article/view/238

- Forés, A., y Grané, J. (Eds.). (2013). La resiliencia en entornos socioeducativos: sentido, propuestas y experiencias. Recuperado de: https:// books.google.com.co/books? id=WvekDwAAQBAJ\&pg =PT2\&dq=f ores $+y+$ gran $\%$ C $3 \%$ A $9 \& h 1=e s-419 \& s a=X \& v e d=0$ ahUKEwjz0Z_bznoAhUKmuAKHdFbBCkQ6AEIKDAA\#v=onepage \&q=fores $\% 20 y \% 20$ gran $\% \mathrm{C} 3 \% \mathrm{~A} 9 \& \mathrm{f}=$ false

- Grondin, J. (2008). ¿qué es la hermenéutica?. Retrieved from https://www.marcialpons. es/libros/que-es-la-hermeneutica/9788425425714/

- Guba E. y Linconl y. (2000). Paradigmas en competencia en la investigación cualitativa. Recuperado de http://sgpwe.izt.uam.mx/pages/egt/Cursos/MetodoLicIII/7_Guba Lincoln_Paradigmas.pdf

- Gvirtz, S., y Podestá, M. E. D. (2010). Mejorar la gestión directiva en la escuela. Buenos Aires, AR: Ediciones Granica. Recuperado de: https://books.google.com.co/bo oks?id=DRsmBgAAQBAJ\& printsec $=$ frontcover\&dq $=$ Mejorar+la + gesti $\% \mathrm{C} 3 \% \mathrm{~B} 3 \mathrm{n}+\mathrm{dir}$ ectiva + en + la + escuela + Gvirtz, + S. + y + Podest $\%$ C3\%A1, $+(2010), \& h l=e s-419 \&$ sa $=X \& v e-$ $\mathrm{d}=$ =ahUKEwiDgv7Jv-noAhUOd98KHTxyCv0Q6AEIMjAB\#v=onepage\&q\&f=true

- Henderson y Milstein. (2003). Resiliencia en la escuela. Recuperado de: https://books. google.com.co/books?id=NuMJAAAACAAJ\&dq=inauthor:\%22Nan+Henderson\%22\& hl=es- 19\&sa=X\&ved=0ahUKEwi359DvjYLdAhUOj1kKHe7hDT8Q6AEIKzAA

- Hernández R, Fernández C y Baptista M. (2014) Metodología de la Investigación, sexta edición. Recuperado de http://observatorio.epacartagena.gov.co/wp-content/ uploads/2017/08/metodologia-de-la-investigacion-sexta-edicion.compressed.pdf

- Hinojo, L.F. (2006).Percepción de los equipos directivos de los centros de enseñanza secundaria de Andalucía sobre la formación profesional reglada. Tesis Doctoral. Universidad de Granada. Recuperado de: https://hera.ugr.es/tesisugr/16157850.pdf

- Hurtado de Barrera Y. (2008). Algunos criterios metodológicos de la investigación. Recuperado de http://investigacionholistica.blogspot.com/2008/04/algunos-criteriosmetodolgicos-de-la.html 
- Hurtado de Barrera Y. (2012). Metodología de la Investigación. Guía para la comprensión holística de la ciencia. Cuarta edición. Bogotá- Caracas. Ediciones Quirón.

- Ministerio de Educación Nacional. (1994). Ley General de Educación. Recuperado de: https://www.mineducacion.gov.co/1621/articles-85906_archivo_pdf.pdf

- Ministerio de Educación Nacional. (2008). Guía 34. Guía para el mejoramiento institucional de la autoevaluación al plan de mejoramiento. ISBN: 978-958-691-306-5 Copy Right 2008 primera edición.

- Ministerio de Educación Nacional. (2016). Manual de funciones del directivo docente. Resolución 09317 del 6 de mayo de 2016 y anexo 1. Recuperado de: https://www. mineducacion.gov.co/1759/articles-357013_recurso_1.pdf

- Puig G y Rubio J. (2013). Manual de resiliencia aplicada. Recuperado de: https://books. google.com.co/books?id=HCY1BQAAQBAJ\&printsec $=$ frontcover\&dq $=$ manual $+\mathrm{de}+$ res iliencia + aplicada\&hl=es-419\&sa=X\&ved=0ahUKEwjP15K-X-noAhVSneAKHVuZBA 8Q6AEIKDAA\#v=onepage \&q=manual\%20de $\% 20$ resiliencia $\% 20$ aplicada $\& \mathrm{f}=$ false

- Quiñonez, R. M. (2006). Creatividad y resiliencia: Análisis de 13 casos colombianos. Tesis Doctoral. Universidad Autónoma de Madrid. Facultad de Formación de Profesorado y Educación. Recuperado de: https://repositorio.uam.es/xmlui/handle/10486/2631

- Rivas. M. S. (2012). Fortalezas de carácter y resiliencia en estudiantes de Medicina de la Universidad de los Andes, Mérida, Venezuela. Tesis Doctoral. Universidad Autónoma de Madrid. Facultad de Medicina; Universidad Autónoma de Madrid. Departamento de Psiquiatría. Recuperado de: https://repositorio.uam.es/xmlui/handle/10486/11241

- Sánchez, F.M. (2015). Elementos de las historias de vida que influyen en la elección profesional de los maestros de educación infantil en formación. Tesis Doctoral. Universidad Complutense, Madrid. Recuperado de: https://eprints.ucm.es/30831/

- Secretaria de Educación Bucaramanga. (2018). Página oficial. Recuperado de: http:// www.seb.gov.co/wp_educacion/?p=219

- UNESCO. (1996). Informe La Educación encierra un tesoro. Recuperado de: https:// unesdoc.unesco.org/ark:/48223/pf0000109590_spa

- UNESCO (1999). Cassasus. Informe a la UNESCO. La gestión en busca del sujeto. Marcos conceptuales para el análisis de los cambios en la gestión de los sistemas educativos. Recuperado de: http://unesdoc.unesco.org/images/0011/001176/117612so. pdf

- UNESCO (2000). Gestión educativa estratégica módulo 2. IIPE. Recuperado: https:// unesdoc.unesco.org/ark:/48223/pf0000159155?posInSet=1\&queryId=7bcc2cd7-8e1842d6-8607-1df7c3060457

- UNESCO. (2015). Educación 2030, Declaración de INCHEON. Recuperado de: http:// 
unesdoc.unesco.org/images/0024/002456/245656s.pdf

- Valle J y Martínez C. (2010). La dirección de centros escolares en Europa en perspectiva comparada ¿De los modelos tradicionales a un "meta-modelo" supranacional? Recuperado de: http://www.saece.com.ar/relec/revistas/1/art5.pdf 